\title{
Calendar of Events
}

\section{IDS 2013}

First International Conference IDS2013 - Amazonia Iquitos, Peru, 17-19 July 2013

www.ids2013.pe

\section{ISSW 2013}

$13^{\text {rd }}$ International Ship Stability Workshop

Brest, Franc, 23-26 September 2013

http://issw13.sciencesconf.org/

\section{COPINAVAL 2013}

XXIII Pan-American Conference on Naval Engineering, Maritime Transports and Port Engineering Margarita, Venezuela, 30 September-04 October www.ipen.org.br

\section{IMAM 2013}

$15^{\text {th }}$ International Congress of the International Maritime Association of the Mediterranean

La Coruña, Spain, 14-17 October 2013

www.imamhomepage.org/imam2013/

\section{PRADS 2013}

$12^{\text {th }}$ International Symposium on Practical Design of Ships and Other Floating Structures, CECO, Changwon City, Gyeongnam, Korea, 20-25 October 2013 www.prads2013.org

\section{SNAME 2013 Annual Meeting}

Hyatt Regency, Bellevue, WA, 6-8 November 2013 www.sname.org 